\title{
Response Variability of Neurons in Primary Visual Cortex (V1) of Alert Monkeys
}

\author{
Moshe Gur, ${ }^{1,2}$ Alexander Beylin, ${ }^{1}$ and D. Max Snodderly ${ }^{2,3}$ \\ ${ }^{1}$ Department of Biomedical Engineering, Technion, Israel Institute of Technology, Haifa 32000, Israel, 2Schepens Eye \\ Research Institute, Boston, Massachusetts 02114, and ${ }^{3}$ Department of Ophthalmology and Program in Neuroscience, \\ Harvard Medical School, Boston, Massachusetts 02115
}

\begin{abstract}
Response variability of neurons limits the reliability and resolution of sensory systems. It is generally thought that response variability in the visual system increases at cortical levels, but the causes of the variability have not been identified. We have measured the response variability of neurons in primary visual cortex (V1) of alert monkeys. We recorded from 80 single cells distributed over all V1 layers and from 8 parvocellular cells of the lateral geniculate nucleus. All cells were stimulated with a bar of near-optimal orientation, color, and dimensions while continuously monitoring the eye movements of fixation. To minimize the effects of eye movements, responses that occurred while the eye was relatively steady were selected for analysis. The impulses elicited by each stimulus presentation
\end{abstract}

were counted, and the variance and coefficient of variation were computed. Both measures of response variability were much lower than reported previously for V1 cells of both alert and anesthetized monkeys. Our data show that fixational eye movements cause a large component of response variance in alert monkeys. Moreover, the reliability of V1 neurons is not obviously degraded compared with lateral geniculate nucleus cells. The high reliability of neurons in alert monkeys is consistent with expectations from conventional biophysical models, and it suggests that activity in a modest number of neurons may suffice to form a perceptual decision.

Key words: striate cortex; monkey; alert; single cells; response variability; vision
Response variability of single neurons is assumed to limit the sensitivity and resolution of sensory systems (Werner and Mountcastle, 1963; Heggelund and Albus, 1978; Tolhurst et al., 1983; Bradley et al., 1987; Scobey and Gabor, 1989; Vogels et al., 1989). Understanding the nature and origins of this variability may facilitate relating performance of sensory neurons to sensory capacities of the organism (Bradley et al., 1987; Scobey and Gabor, 1989; Vogels, 1990; Zohary et al., 1994). It is generally thought that the performance of cortical cells is highly variable; identical stimuli elicit responses that vary randomly in amplitude from presentation to presentation. Studies of striate cortex (V1) cells in anesthetized and paralyzed cats (Bradley et al., 1987; Rose, 1979; Dean, 1981; Tolhurst et al., 1983; Scobey and Gabor, 1989; Swindale and Mitchell, 1994) and monkeys (Schiller et al., 1976; Tolhurst et al., 1983) have shown that response variance of single cells is equal to or greater than mean response strength.

In contrast, response variance in subcortical structures, the retina (Croner et al., 1993), and the lateral geniculate nucleus (LGN) (Schiller et al., 1976; Edwards et al., 1995) of anesthetized monkeys is substantially lower, and the variance does not increase much with response strength (Croner et al., 1993; Edwards et al., 1995). These results suggest that the transformation between the LGN and V1 may be the locus where the large response variability arises.

Surprisingly, responses of V1 neurons in alert monkeys have been considered to be no more reliable than responses in anes-

\footnotetext{
Received Nov. 19, 1996; revised Feb. 3, 1997; accepted Feb. 5, 1997.

This work was supported by the Fund for the Promotion of Research at the Technion to M.G. We thank Marita Mullan-Sandstrom, Richard I. Land Jr. and Charles Simmons for skilled technical assistance.

Correspondence should be addressed to Dr. Moshe Gur, Department of Biomedical Engineering, Technion, Israel Institute of Technology, Haifa 32000, Israel.

Copyright (C) 1997 Society for Neuroscience $0270-6474 / 97 / 172914-\bullet \$ 05.00 / 0$
}

thetized animals (Vogels et al., 1989; Snowden et al., 1992; Softky and Koch, 1993). The apparent similarity between anesthetized and alert preparations is misleading, however, if variability in the two cases is generated by different sources. Uncontrolled fluctuations in responsiveness can be caused by sleep or anesthesia for neurons in the LGN (Maffei and Rizzolatti, 1965; Coenen and Vendric, 1972) and visual cortex (Bartlett and Doty, 1974; Ikeda and Wright, 1974; Livingstone and Hubel, 1981), and prolonged paralysis has similar effects (Mountcastle et al., 1969). In contrast, using alert animals has the advantage that a relatively steady physiological state may be assumed. Nevertheless, a different source of variability must be considered: the fixational eye movements of the animal. It is crucial that eye position, during data collection, is carefully monitored; otherwise, the idiosyncratic fixational eye movements can unpredictably modulate the stimulusgenerated responses (Gur and Snodderly, 1987, 1997; Snodderly and Gur, 1995).

Unlike experimental data for cortical cells, theoretical models of cellular spike generation mechanisms predict a low response variability (Knight, 1972; Softky and Koch, 1993). To reconcile the high variability reported for cortical cells with biophysical constraints, Softky and Koch (1993) had to assume an unusual, and perhaps unrealistic (Shadlen and Newsome, 1994), model involving either strong dendritic nonlinearities or strong synchronization among individual synaptic events. In this paper, we show that the response variance of cortical cells of alert monkeys is dramatically reduced if the influence of eye movements is minimized. Given these results, biophysical models need to account for less variability than previously thought.

To minimize the effects of fixational eye movements, we have recorded from single cells in V1 of alert monkeys but considered only responses generated while eye position remained relatively 


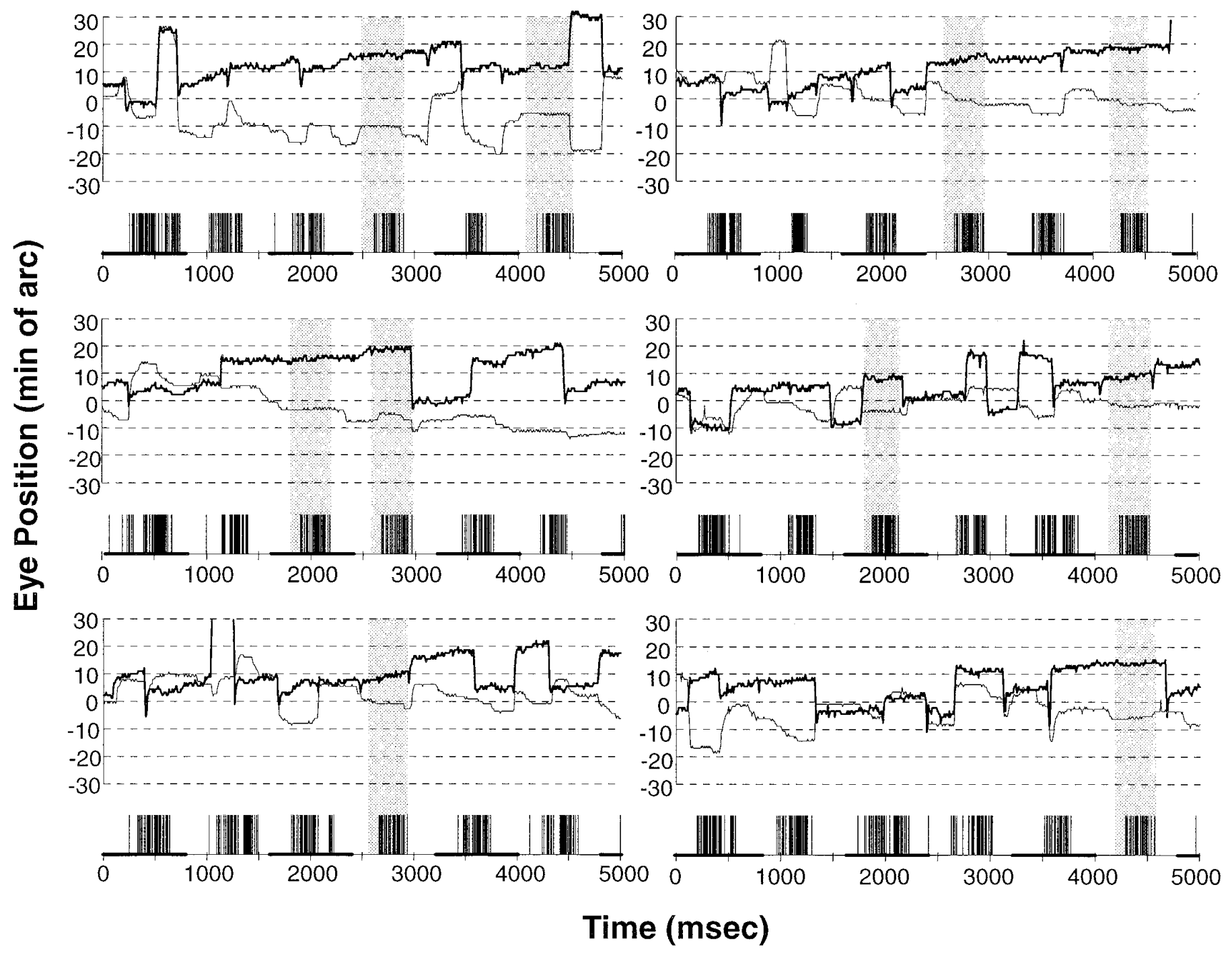

Figure 1. Complete records of six fixation trials recorded with no compensation for eye position (nonstabilized). Short vertical lines denote action potentials. Continuous lines display vertical (thick line) and horizontal (thin line) eye position. A direction-selective cell in layer 6 (2494r008) was stimulated by a $5 \times 83 \mathrm{~min}$ vertical green bar sweeping repeatedly left to right for $800 \mathrm{msec}$. Selected responses, marked with gray rectangles, are those generated during pauses in eye movements when eye position did not vary by more than \pm 3 min during the period from 100 msec before the response until the response ended.

steady. Under these conditions, we find that neuronal responses are more reliable than previous results from either alert or anesthetized preparations. In addition, the variance of cortical responses is within the range of variance of subcortical responses. Thus, the enhanced response selectivity of cortical neurons continues to display reliable functioning in spite of increased anatomical complexity.

\section{MATERIALS AND METHODS}

Data acquisition. Single-unit recordings were made from three adult female monkeys. The recording sites were histologically verified (Snodderly and Gur, 1995) for 61 V1 and 8 LGN cells in one Macaca mulatta and one Macaca fascicularis. Nineteen additional V1 cells were studied in another Macaca mulatta monkey that is still undergoing experiments. These cells were assigned to V1 based on the visual field location of their receptive fields (RFs) and the location of the craniotomy and to cortical layers based on physiological criteria (Snodderly and Gur, 1995). Details of training and recording procedures have been published (Snodderly and Kurtz, 1985; Gur and Snodderly, 1987; Snodderly and Gur, 1995). Briefly, monkeys were trained to fixate on an LED for $5 \mathrm{sec}$. Eye position was monitored by a double Purkinje image eye tracker (2-3 minarc resolu- tion) and sampled at $120 \mathrm{~Hz}$ by computer. The time of occurrence of nerve impulses was recorded to the nearest $0.1 \mathrm{msec}$.

Visual stimuli were generated by a Truevision ATVista video graphics adapter at a $60 \mathrm{~Hz}$ frame rate. Stimuli were red, green, blue, gray, or black bars of optimal orientation, color, and spatial configuration, $0.9 \log$ units brighter or darker than the background of 1 candela $/ \mathrm{m}^{2}$. Chromatic stimuli were generated by activation of individual guns of the color video monitor, a Barco 7351 or a Mitsubishi HL6605. Incremental (bright) stimuli were presented on a neutral gray background; decremental stimuli were presented on a background of a single color (Snodderly and Gur, 1995). The bars were swept across the RF in a direction orthogonal to the long axis of the RF at $1.5-4 \% \mathrm{sec}$. For $69 \%$ of the cortical cells, the eye position signal from the eye tracker was added to the stimulus position signal from the computer at the beginning of each video frame to compensate for eye movements (Gur and Snodderly, 1987, 1997; Snodderly and Gur, 1995).

Data analysis. The total count of spikes generated during one sweep of a bar across the RF was taken as a measure of the response strength. This measure allows for comparison with many previous studies, including those using alert monkeys (Vogels et al., 1989; Snowden et al., 1992; Britten et al., 1993). Responses were selected for analysis by visual inspection of records of eye position during the $5 \mathrm{sec}$ trials. Responses 


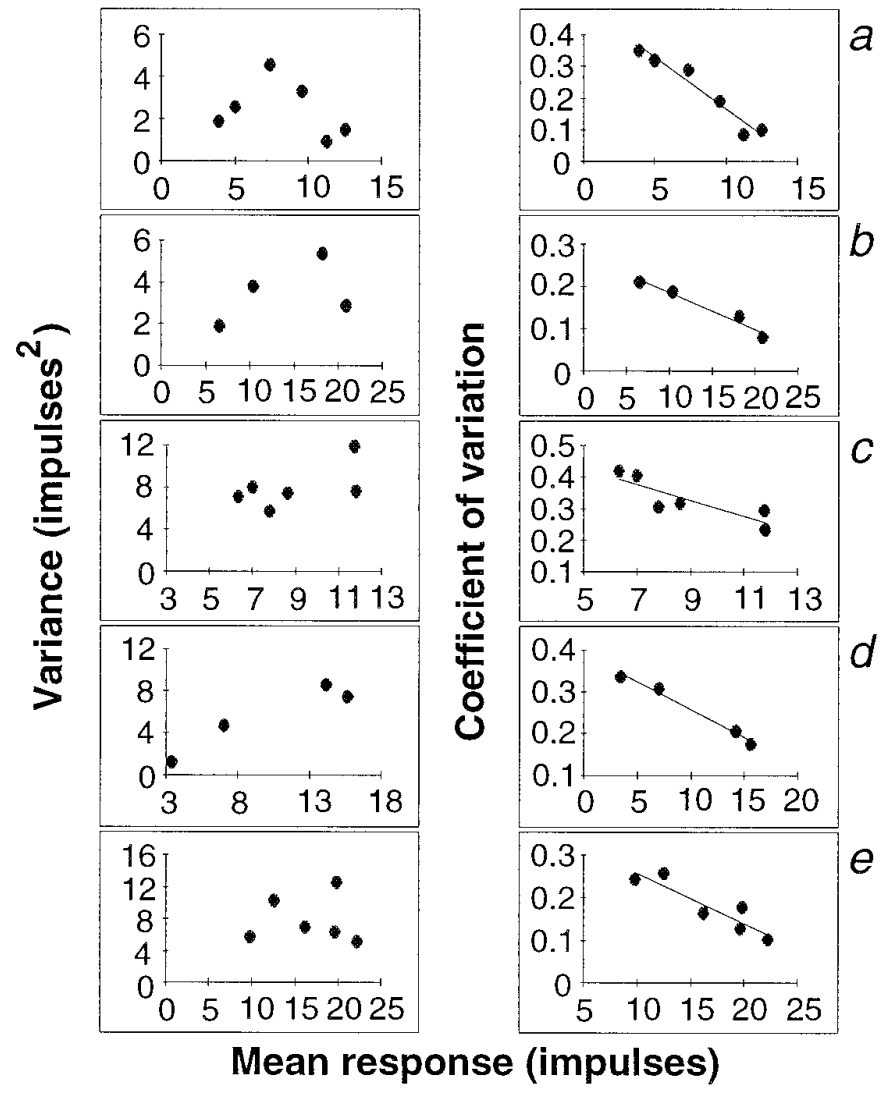

Figure 2. Variance and CV as a function of response strength calculated for five individual cells. Different response magnitudes were generated either by various contrasts $(a, b)$ or orientations $(c-e)$. All cells were orientation-selective. $a$, A spontaneously active layer $4 \mathrm{C}$ cell (2780a021). Contrast range, 20-95\% . b, A "silent" layer 4B cell (0994a006). Contrast range, 50-93\%. c A silent layer 3 cell (3180a000). Optimal orientation, $140^{\circ}$; range, $80-180^{\circ}$. $d$, A silent layer $4 \mathrm{C}$ cell (1294a028). Optimal orientation, $37^{\circ}$; range, $0-73^{\circ}$. $e$, A spontaneously active layer $4 \mathrm{C}$ active cell (1226a001). Optimal orientation, $61^{\circ}$; range $61-95^{\circ}$. Regression lines for the CV data in the right column are indicated: $r=0.97, p<0.005(a) ; r=$ $0.98, p<0.02(b) ; r=0.87, p<0.05(c) ; r=0.98, p<0.01(d) ; r=0.91$, $p<0.02(e)$.

were included in the analysis if total displacement in eye position varied no more than \pm 3 min during the $100 \mathrm{msec}$ preceding the response (to allow for response latency) and during the response. For each cell studied, at least 6 and usually 10 or more, responses were selected for calculation of response mean, response variance, and coefficient of variation $(\mathrm{CV})(\mathrm{SD} /$ mean).

\section{RESULTS}

\section{Effects of eye movements}

Experimental records displaying complete data from six behavioral fixation trials are shown in Figure 1. The stimulus sweeps across the RF of the cell six times in each trial while the monkey is attempting to maintain steady fixation. The graphs depict occurrence times for each nerve impulse along with a highresolution record of horizontal and vertical eye position. The fixational eye movements during the trials consist of slow drifts interposed with small ( $<30 \mathrm{~min}$ ) fixational saccades and back-toback saccades (clusters) with spike-like waveforms. These spikelike saccade clusters are common during the involuntary movements of fixation but absent when shifting gaze with voluntary saccades (Snodderly, 1987). As we have demonstrated previously (Snodderly and Gur, 1995; Gur and Snodderly, 1997), and as can be seen here, both slow and fast eye movements influence neural responses.

From the available 36 responses, 10 (Fig. 1, gray rectangles) were selected from time periods with minimal eye movement. The mean of the selected responses was 38.9 spikes with a variance of 21.2 spikes $^{2}$. To demonstrate the effects of eye movements, we took the first 10 consecutive responses, not selecting for pauses in eye movements, and found that although the mean response (40.4 spikes) was not significantly different $(p=0.37)$, the variance $\left(189.4\right.$ spikes $^{2)}$ was significantly larger $(p<0.005)$. Because for all trials, eye position was restricted to a rather small window $( \pm 30$ min), this example shows that a small fixation window is not sufficient to prevent a powerful influence of fixational eye movements on the response variability of V1 neurons. To minimize variability, it is necessary to review a continuous record of eye position so that only unaffected responses are selected.

\section{Response variability of individual cells}

Response variance and $\mathrm{CV}$ as a function of response strength were measured for $21 \mathrm{~V} 1$ cells. Results for five representative cells are shown in Figure 2. Different response amplitudes were elicited by varying stimulus contrast (Fig. $2 a, b$ ) or stimulus orientation $(c-e)$. For all cells, variance was not systematically affected by response strength (left panels). This is the case whether responses were generated by different contrasts $(a, b)$ or different orientations $(c-e)$. The lack of a strong dependence of response variance on response amplitude led to significant decreases of the $\mathrm{CV}$ with increases in response amplitude, as can be seen in the right column.

\section{Comparisons across cells}

Although response variance in individual cells seemed to be independent of response strength, we considered the possibility that this could be attributable to the limited response range of the data from our individual cells. An alternative approach was to use the wider range afforded by analyzing data across our cell population to determine whether variance correlated with mean response (cf. Croner et al., 1993). This analysis also made it possible to compare our results with previously published data (Vogels et al., 1989; Snowden et al., 1992).

We studied response variance as a function of mean response amplitude for $80 \mathrm{~V} 1$ neurons and 8 parvocellular LGN cells. Recordings were made from all cortical layers. A total of $65 \mathrm{~V} 1$ cells were assigned to cortical layers as follows ( $\mathrm{L}$ indicates layer): L2/3, 16; L4A, 4; L4B, 14; L4C, 17; L4C boundaries, 1 top, 1 bottom; L5, 5; L6, 7. The other 15 V1 cells were not assigned. Results from all cells are depicted in Figure 3 in a log-log plot in which each point represents one cell's response to optimal stimulation. All data were selected to minimize interference from eye movements, as illustrated in Figure 1.

For 55 of 80 cortical cells, data were taken while compensating on-line for eye movements ("image stabilization") and for the remaining cells, there was no compensation for eye movements. Visual inspection of the graph showed no systematic differences between cells recorded under compensated and noncompensated conditions (Fig. 3, solid and open squares, respectively); thus, all were analyzed together. Note that using on-line compensation is beneficial when the spatial properties of the cell are demanding (e.g., strong end and side inhibition) and when the spatial phase of the stimulus is relevant (Gur and Snodderly, 1997). However, in this dataset, none of the cells studied without compensation were end-inhibited, and we considered only the total response without 


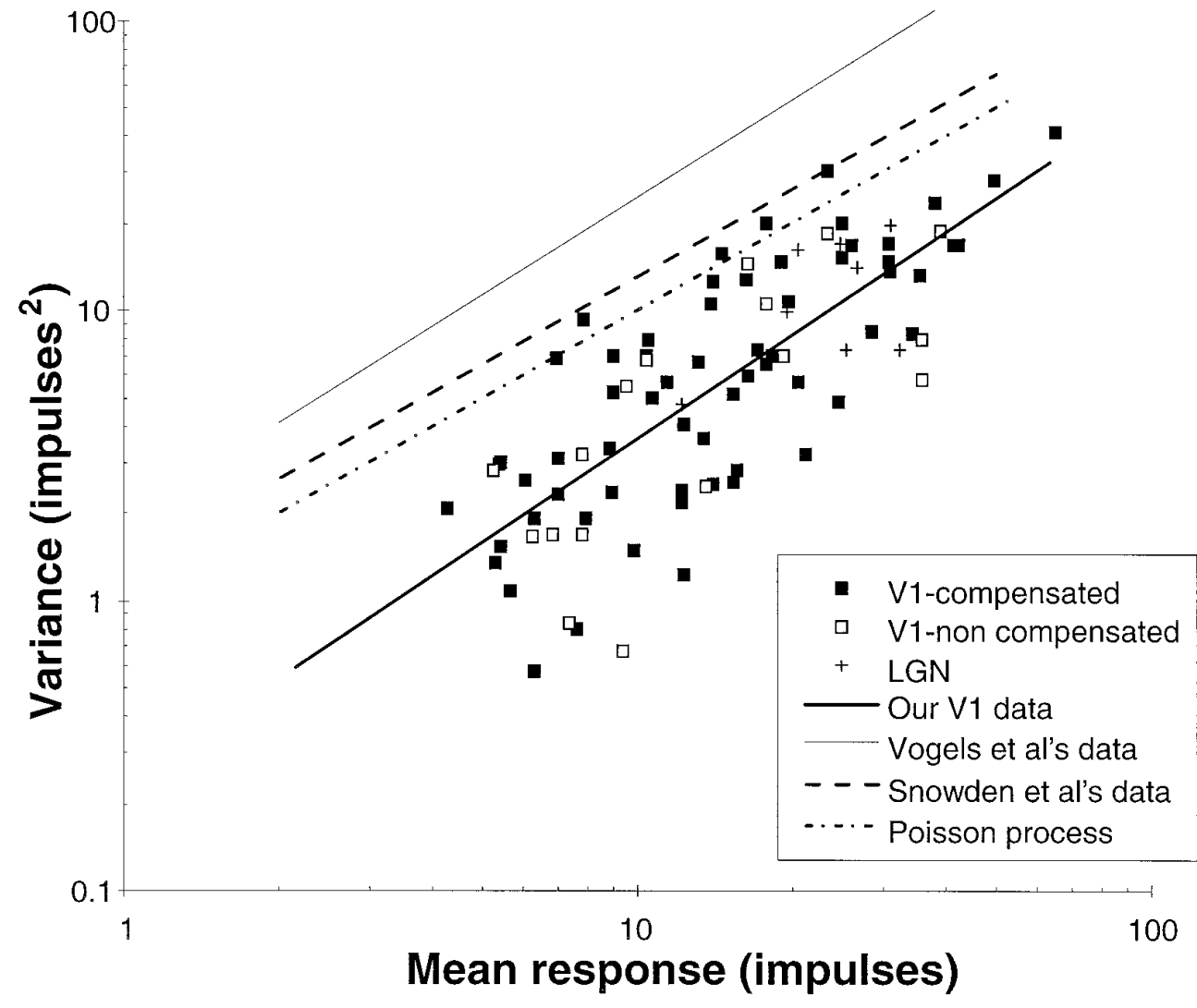

Figure 3. Relationship between variance and response strength for our total V1 (80 cells) and LGN (8 cells) populations. Regression line for our V1 single cells (thick line; intercept $=0.24$, slope $=1.17)$ is compared with regression lines from earlier data. Thin line indicates relationship calculated by Vogels et al. (1989) (intercept = 1.9; slope $=1.11)$. Dashed line represents mean values calculated from analyses of individual cells by Snowden et al. (1993) (intercept $=1.08$, slope $=1.21$ ). Dotdash line represents a Poisson process. regard to the exact position (spatial phase) of the moving stimulus. Thus, it is not surprising that there were no differences between the "compensated" and "noncompensated" groups.

A regression analysis of the data was performed using only the single units recorded in V1. Consistent with earlier work, the relationship between response variance and response strength for our V1 single-cell sample is well described by the power function:

$$
\text { Variance }=\mathrm{a} \cdot(\text { mean response })^{b} .
$$

This function corresponds to a line on a log-log plot (Fig. 3) with intercept $a$ and slope $b$. The best-fitting line for the logtransformed data yielded an intercept of $a=0.24$ and a slope of $b=1.17$, with a correlation coefficient $r=0.76(p<0.001)$. The individual data points in Figure 3 also show that response variability of the LGN units is similar to that of V1 neurons with similar response magnitudes. The average interspike interval for all cortical units was $13.1 \pm 6$ msec.

For comparison with other data obtained from V1 of alert monkeys, the regression line calculated by Vogels et al. (1989) for responses of single neurons to large grating patterns is plotted (Fig. 3, thin line). In addition, the line specified by the mean values of the intercept and slope of responses of individual V1 cells to random dot patterns is depicted (Snowden et al., 1992). We consider these mean values to be reasonable measures for comparison with our data, because Britten et al. (1993) have shown that the average of single cell variance-response relationships correctly describes the population response. The slopes of the regression lines are similar for all three data sets. However, the distances between the lines, which indicate differences in response variance for a particular response strength, demonstrate that both earlier studies found a consistently higher variance.

\section{Contributions of eye movements to response variance}

The most straightforward explanation of the larger variance in the earlier data is that it was generated by the eye movements of fixation, as illustrated in Figure 1. To test this explanation, we analyzed data from 19 randomly selected cells, using 10 responses from each cell. Unlike our other analyses, these data were not selected to minimize the effects of fixational eye movements on individual responses. We merely required that eye position remain within a \pm 40 min window for all responses, which is similar to the approach used in other laboratories. The results are illustrated in Figure 4, along with the regression lines from Figure 3.

When only an eye position window was imposed (Fig. 4, open circles), variance was higher than when data were selected to minimize effects of the small eye movements of fixation (thick line). The regression line for data with the eye position window (dot-dash line) is shifted upward, and its intercept (0.81) is very different from the intercept of our edited data (thick line). In fact, it is much closer to the intercept of Snowden et al. (1992) (1.08). The similarity between our unedited data and the results of Snowden and co-workers (dashed line) is probably attributable to having permitted a similar amount of eye movement. Snowden et al. estimated the extent of eye movement in their experiments by measuring eye position at the end of a set of trials and then by computing the SD across trials. Assuming a normal distribution, one can calculate that eye position of their monkeys at the end of the trial could vary within a range of $\pm 0.4^{\circ}$. This value is an underestimate, because it ignores within-trial variation; thus, a more realistic assessment would be closer to the $\pm 0.67^{\circ}$ window size we used. For comparison, Vogels et al. (1989) only required their monkeys to maintain fixation within a rather large window of 
Figure 4. Relationship between response variance and response strength for $19 \mathrm{~V} 1$ cells (open circles), the responses for which were not limited to those occurring during eye pauses. Eye position was kept within a $\pm 40 \mathrm{~min}$ window. Regression line for these nonselected data (dot-dash line) (intercept $=$ 0.81 ; slope $=1.19$ ) is compared with regression lines presented in Figure 3.

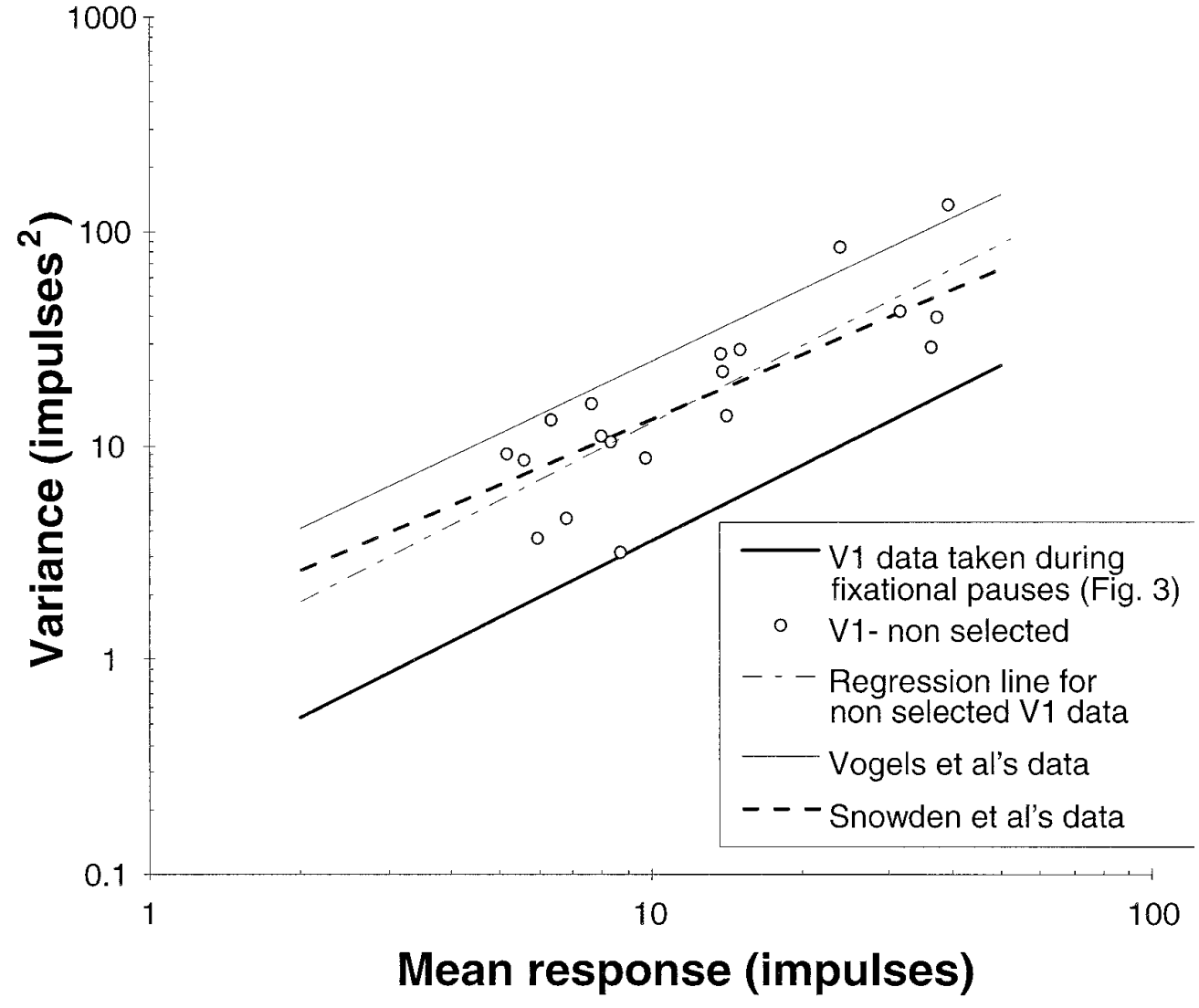

$\pm 2.5^{\circ}$ (Vogels and Orban, 1990), and they found much higher response variance.

The overall pattern is that variability is linked directly to the amount of eye movement allowed during data collection. The highest variability is found when a large fixation window is used (Vogels et al., 1989; Vogels and Orban, 1990). An intermediate level of variability results from tightening the fixation criteria (Snowden et al., 1992) (Fig. 4; our unedited data). The lowest variance occurs when data are rigorously selected to minimize effects of eye movements (Fig. 3; our data).

The regression lines for the data of Snowden et al. and for our unedited data (Fig. 4) are similar to the relationship expected for a Poisson distribution (slope and intercept $=1$ ). This function may be a reflection of the random nature of the interaction between fixational eye movements and stimulus position.

Comparison with responses from anesthetized animals

We have also compared our data with response variability of neurons in V1 of anesthetized and paralyzed animals measured with similar stimuli (Schiller et al., 1976; Heggelund and Albus, 1978). We calculated the CV for each of our V1 and LGN units. In Figure 5, we compare the distribution of the CV data from alert monkeys selected to minimize effects of eye movements (top) with data from Schiller and colleagues (1976) from anesthetized, paralyzed monkeys (bottom). The mean CV of our sample (0.18) is approximately half that of the total sample from Schiller and co-workers $(0.35)$. This difference is highly significant $(p<0.001)$. The mean CV of V1 neuronal responses studied in anesthetized cats (0.35) (Heggelund and Albus, 1978) is the same as the mean for anesthetized monkeys; thus, responses from anesthetized cats are also more variable than our findings. The difference between the mean CV of our LGN and V1 samples is not significant, which suggests that there is not a sudden, large increase in variability in the transition from thalamus to cortex. However, data from a larger number of LGN units would be necessary to examine the possibility of systematic small differences.

Rose (1979) has suggested another measure of response variability - response reliability — which is the mean divided by the SD (the inverse of the CV). Thus, a high index indicates good reliability. This index, averaged across our V1 sample (mean = 6.65 ; $\mathrm{SD}=2.25)$, is higher than that reported by Rose (mean $=$ 4.64; $\mathrm{SD}=2.75$ ) for $\mathrm{V} 1$ cells recorded in anesthetized and paralyzed cats. By every measure, the responses of V1 neurons in alert monkeys are more reliable than those in anesthetized animals, once the contribution of eye movements has been minimized.

\section{DISCUSSION}

The amount of variability, or noise, in spike trains is an important issue, because it constrains the ability of neurons to transmit information and thus shapes our modeling of information processing in the nervous system (Vogels, 1990; Softky and Koch, 1993; Shadlen and Newsome, 1994; Zohary et al., 1994). Numerous previous studies have concluded that response variability of cortical cells is large (Schiller et al., 1976; Rose, 1979; Tolhurst et al., 1983; Bradley et al., 1987; Scobey and Gabor, 1989; Vogels et al., 1989; Swindale and Mitchell, 1994; Edwards et al., 1995). Our results show that minimizing effects of eye movements in the alert state reduces the response variability of V1 cells to a level similar to that of LGN neurons (see Fig. 3).

\section{Factors influencing response variability}

The identification of eye movements as an important source of response variability in alert monkeys implies that different mech- 


$$
\begin{array}{ll}
\text { mean (LGN) } & \text { mean (V1) } \\
\overline{c v}=0.15 & \frac{\bar{c} v}{\bar{c}}=0.18
\end{array}
$$
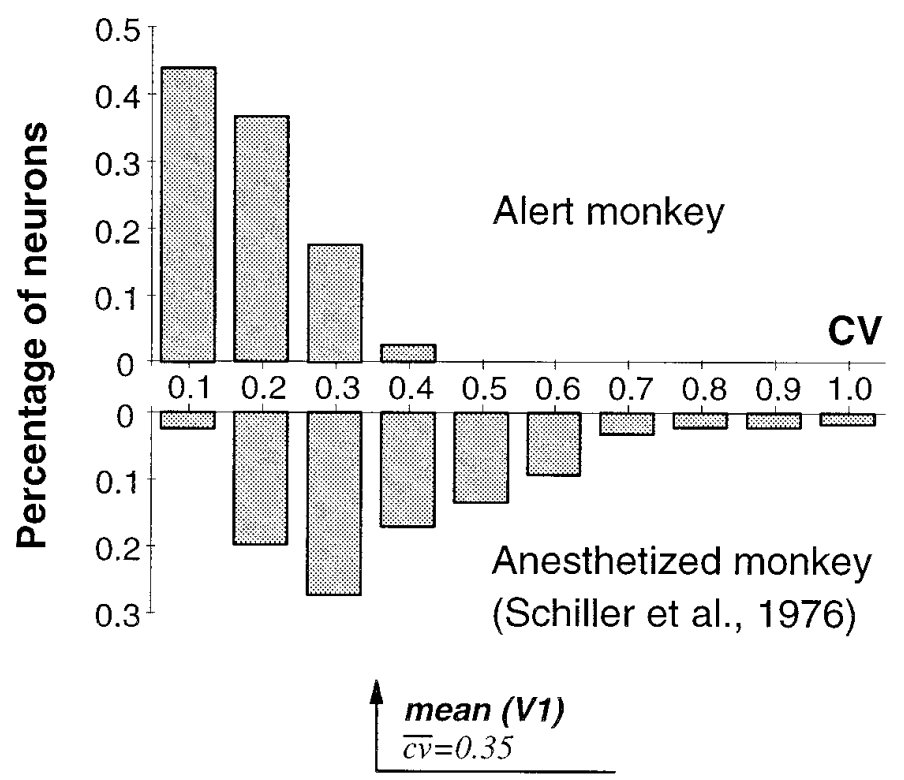

Figure 5. Normalized histograms of CV for our V1 single cells (top panel, $n=80$ ) and Schiller et al.'s (1976) data (bottom panel, $n=333$ ). Arrows indicate the mean CV for each sample. Histograms for our LGN data $(n=$ 8) are not shown.

anisms must underlie the high variability of data from anesthetized animals for which the eyes are paralyzed. It has been noted repeatedly that there are slow changes in responsivity in anesthetized animals that contribute strongly to response variability (Rose, 1979; Tolhurst et al., 1983; Bradley et al., 1987). These changes may reflect fluctuations in synaptic activity traveling in waves through the cortical network (Arieli et al., 1996).

One possibility is that the consistent responses we obtain from V1 cells are related to the strong inhibition that we believe is applied tonically to many "silent" V1 cells in alert animals (Snodderly and Gur, 1995). Once a stimulus is effective enough to bring the input of the network above the threshold of the cell, firing is quite robust and consistent. In fact, the full variability of synaptic input to cortical cells in alert animals may only be evident in determining threshold. This is consistent with the fact that generation of weaker responses with nonoptimal stimuli increases the CV (Fig. 2) (see also Schiller et al., 1976; Heggelund and Albus, 1978).

\section{Sensory effects of eye movements}

In our experiments, to optimize the responses we selected data when the eye was at rest and the stimulus was sweeping across the RF. Under normal circumstances, when observers inspect an object or a scene, effective stimulation results when the eyes drift across an object or saccade to it, generating for each new position a response in an array of cortical cells. In both experimental and natural situations, the effective stimulus is the transient change in light flux within the RF. The transient responses that are elicited may be more reliable than sustained responses generated under laboratory conditions (Bair and Koch, 1996). Thus, it is possible that our data mimic natural conditions, because they are mostly generated as responses to stimuli of brief durations. Many RFs were quite small so that stimuli swept quickly across them, generating responses lasting only 100-300 msec.

How the visual system distinguishes the effects of eye movements from movements of objects in the external world or other changes in the visual scene is an old and still challenging question (Jung, 1972). Although we have minimized the effects of eye movements by our analysis procedure, we do not wish to imply that the visual system uses a similar selection mechanism to solve this problem. Eye movements have the distinguishing feature that the retinal image of the whole visual scene moves as a single entity, presumably generating an extensive array of synchronous discharges in the brain. In principle, the brain could use this synchrony to help distinguish the occurrence of an eye movement from the movement of an object. Synchronous activation by eye movements needs to be considered as part of theorizing about the role of synchronization in visual processing (Singer and Gray, 1995).

One aspect of this synchrony may be manifested in the results of Snowden et al. (1992), who found that area MT neurons showed no better reliability than V1 neurons, in spite of the fact that MT neurons are thought to pool inputs from many V1 cells (Snodderly and Gur, 1995). If the noise of V1 neurons was uncorrelated from cell to cell, pooling should reduce the noise of MT cells, and it apparently does not. We suggest that the noise of V1 neurons is correlated because of eye movements, and this correlation may limit the effectiveness of pooling by MT neurons for reducing variability (Shadlen et al., 1996).

\section{Implications of our results}

The low residual variability of V1 neurons after minimizing effects of eye movements has at least two other important implications. One relates to spike-generating mechanisms and the variability of spike trains. Because the leaky integrator model for spike generation predicts low variability (Knight, 1972; Softky and Koch, 1993), the large response variability found previously for visual cortex cells has been puzzling and has led to unorthodox models of integration of synaptic input (Softky and Koch, 1993). However, given the low residual variability we have shown, the conventional integrate-and-fire model, together with consideration of the effects of eye movements, should be able to account for more of the spike train characteristics than previously thought possible.

Our results also impact on studies relating single cell responses to perception. An observer making a perceptual judgment could presumably use the information from the most responsive and reliable cells in visual cortex. We propose that our analysis procedure provides an estimate of the activity of the most responsive and reliable cells, because it assures that the stimulus is optimally positioned and moved across the RF. Furthermore, the ability of a nerve cell to discriminate among stimuli is directly proportional to its response variance (Bradley et al., 1987; Scobey and Gabor, 1989); thus, the low variance of the most reliable neurons should result in a finer discriminative capacity than would be judged from the responses of nonoptimally stimulated cells. The availability to the observer of cells with superior discriminative ability implies that fewer cells should be needed to make a perceptual decision (Vogels, 1990). It has been suggested that neuronal pools of $\sim 100$ cells may be needed to form the fundamental signaling units of visual cortex (Shadlen and Newsome, 1994; Shadlen et al., 1996). Perhaps this estimate can be reduced when the influence of eye movements is better understood. 


\section{REFERENCES}

Arieli A, Sterkin A, Grinvald A, Aertsen A (1996) Dynamics of ongoing activity: explanation of the large variability in evoked cortical responses. Science 273:1868-1871.

Bair W, Koch C (1996) Temporal precision of spike trains in extrastriate cortex of the behaving macaque monkey. Neural Comp 8:1185-1202.

Bartlett JR, Doty RW (1974) Response of units in striate cortex of squirrel monkeys to visual and electrical stimuli. J Neurophysiol 37:621-641.

Bradley A, Skottun BC, Ohzawa I, Sclar G, Freeman RD (1987) Visual orientation and spatial frequency discrimination: a comparison of single neurons and behavior. J Neurophysiol 57:755-772.

Britten KH, Shadlen MN, Newsome WT, Movshon JA (1993) Responses of neurons in macaque MT to stochastic motion signals. Vis Neurosci 10:1157-1169.

Coenen AML, Vendric AJH (1972) Determination of the transfer ratio of cat's geniculate neurons through quasi-intracellular recordings and the relation with levels of alertness. Exp Brain Res 44:227-242.

Croner LJ, Purpura K, Kaplan E (1993) Response variability in retinal ganglion cells of primates. Proc Natl Acad Sci USA 90:8128-8130.

Dean AF (1981) The variability of discharge of simple cells in the cat striate cortex. Exp Brain Res 44:437-440.

Edwards DP, Purpura KP, Kaplan E (1995) Contrast sensitivity and spatial frequency response of primate cortical neurons in and around the cytochrome oxidase blobs. Vision Res 35:1501-1523.

Gur M, Snodderly DM (1987) Studying striate cortex neurons in behaving monkeys: benefits of image stabilization. Vision Res 27:2081-2087.

Gur M, Snodderly DM (1997) Visual receptive fields of neurons in primary visual cortex (V1) move in space with the eye movements of fixation. Vision Res 37:257-265.

Heggelund P, Albus K (1978) Response variability and orientation discrimination of single cells in striate cortex of cat. Exp Brain Res 32:197-211.

Ikeda H, Wright MJ (1974) Sensitivity of neurons in visual cortex under different levels of anesthesia. Exp Brain Res 20:417-484.

Jung R (1972) How do we see with moving eyes? Bibl Ophthalmol 82:377-395.

Knight BW (1972) Dynamics of encoding in a population of neurons. J Gen Physiol 59:734-766.

Livingstone MS, Hubel DH (1981) Effects of sleep and arousal in the processing of visual information in the cat. Nature 291:554-561.

Maffei L, Rizzolatti GT (1965) Effects of synchronizing sleep on the responses of lateral geniculate units to flashes of light. Arch Ital Biol 103:609-622.

Mountcastle VB, Talbot WH, Sakata H, Hyvarinen J (1969) Cortical neuronal mechanisms in flutter-vibration studied in unanesthetized monkeys. Neuronal periodicity and frequency discrimination. J Neurophysiol 32:452-484.

Rose D (1979) An analysis of the variability of unit activity in the cat's visual cortex. Exp Brain Res 37:565-604.
Schiller PH, Finlay BL, Volman SF (1976) Short-term response variability of monkey striate neurons. Brain Res 105:347-349.

Scobey RP, Gabor AJ (1989) Orientation discrimination sensitivity of single units in cat primary visual cortex. Exp Brain Res 77:398-406.

Shadlen MN, Newsome WT (1994) Noise, neural codes, and cortical organization. Curr Opin Neurobiol 4:569-579.

Shadlen MN, Britten KH, Newsome WT, Movshon JA (1996) A computational analysis of the relationship between neuronal and behavioral responses to visual motion. J Neurosci 16:1486-1510.

Singer W, Gray CM (1995) Visual feature integration and the temporal correlation hypothesis. Annu Rev Neurosci 18:555-586.

Snodderly DM (1987) Effects of light and dark environments on macaque and human fixational eye movements. Vis Res 27:401-415.

Snodderly DM, Gur M (1995) Organization of striate cortex (V1) of alert, trained monkeys (Macaca fascicularis): ongoing activity, stimulus selectivity, and widths of receptive field activating regions. J Neurophysiol 74:2100-2125.

Snodderly DM, Kurtz D (1985) Eye position during fixation tasks: comparison of macaque and human. Vis Res 25:83-98.

Snowden RJ, Treue S, Andersen RA (1992) The response of neurons in areas V1 and MT of the alert rhesus monkey to moving random dot patterns. Exp Brain Res 88:389-400.

Softky WR, Koch C (1993) The highly irregular firing of cortical cells is inconsistent with temporal integration of random EPSPs. J Neurosci 13:334-350.

Swindale NV, Mitchell DE (1994) Comparison of receptive field properties of neurons in area 17 of normal and bilaterally amblyopic cats. Exp Brain Res 99:399-410.

Tolhurst DJ, Movshon JA, Dean AF (1983) The statistical reliability of signals in single neurons in cat and monkey visual cortex. Vis Res 23:775-785.

Tomlo GJ, Crapper DR (1974) Neuronal variability: non-stationary responses to identical visual stimuli. Brain Res 79:405-418.

Vogels R (1990) Population coding of stimulus orientation by striate cortical cells. Biol Cybern 64:25-31.

Vogels R, Orban GA (1990) How well do response changes of striate neurons signal differences in orientation: a study in the discriminating monkey. J Neurosci 10:3543-3558.

Vogels R, Spileers W, Orban GA (1989) The response variability of striate cortical neurons in the behaving monkey. Exp Brain Res 77:432-436.

Werner G, Mountcastle VB (1963) The variability of central neural activity in a sensory system, and its implications for the central reflection of sensory events. J Neurophysiol 26:958-977.

Zohary E, Shadlen MN, Newsome WT (1994) Correlated neuronal discharge rate and its implications for psychophysical performance. Nature 370:140-143. 